\title{
Notas para una discusión sobre el estudio de registros cartográficos coloniales
}

\section{( María Laura Pensa*}

Fecha de recepción: 18 de mayo de 2020. Fecha de aceptación: 20 de septiembre de 2020

Palabras clave

estudios coloniales estudios visuales cartografía teoría

\section{Resumen}

Este artículo constituye un resumen o bibliografía anotada de los principales aportes en relación al estudio de mapas y otros documentos cartográficos coloniales desde distintas disciplinas sociales. Se seleccionan y ponen en discusión argumentos provenientes de la antropología, los estudios culturales, coloniales, visuales y cartográficos para reflexionar acerca de la naturaleza de las imágenes cartográficas y una posible metodología de análisis. Sugiero que en función de su naturaleza híbrida, un estudio que contemple variables tanto textuales como visuales nos conducirá al mejor entendimiento de estos documentos y sus posibilidades como fuentes de información.

\section{Notes for a conversation on the study of colonial cartographic} records

\begin{abstract}
Key words

colonial studies visual studies cartography theory

This article constitutes a summary or annotated bibliography on the main contributions towards the study of maps and other cartographic documents from different social disciplines. Diverse ideas coming from anthropology, cultural, colonial, cartographic and visual studies are selected and put into a discussion that reflects on the nature of cartographic images and a possible analysis methodology. It is suggested that by virtue of their hybrid nature, a study that contemplates both textual and visual features will lead us to a better understanding of these documents and their possibilities as sources of information.
\end{abstract}

\section{Introducción}

La producción del espacio es una problemática que ocupa a los estudios coloniales desde distintas perspectivas. Partiendo del ya célebre trabajo de Edmundo O'Gorman (1958), en el que se discute la premisa seminal acerca del descubrimiento de América y se desentraña la génesis de lo que el autor 
llama su invención en el plano de lo discursivo, en los 60 años que nos separan de la publicación de esta obra, distintos autores han hecho propia la tarea de iluminar los procesos por los cuales se demarcan y diferencian ciertas regiones amerindias. Con el avance de la discusión y la influencia de numerosas corrientes intelectuales, se incorporaron perspectivas más alejadas del campo discursivo, centradas en la producción y reproducción material de espacios y personas (Seed, 2001; Verdesio, 2001a; Gordillo, 2004 y Nemser, 2017), que sin embargo no renunciaron a conjugar en sus análisis la materialidad de los procesos con la representación cultural de los mismos. En este artículo, propongo reflexionar acerca del tratamiento que ha tenido una forma específica de la representación, los registros cartográficos visuales -llamados rápidamente mapas- producidos durante el período colonial. Propongo que estos documentos comparten convenciones, silencios y posibilidades con las fuentes textuales, pero poseen características propias en función de su naturaleza visual. Por esto, a partir de una discusión que considere algunos aportes de los estudios espaciales, coloniales y visuales, reflexionaremos sobre las posibilidades para el tratamiento de estas fuentes.

\section{Reconocimiento del terreno}

A partir de la década del ochenta, una serie de trabajos provenientes de la filosofía, la geografía cultural, y la antropología social denotan el interés creciente por las preocupaciones en torno a categorías como espacio y lugar, pero también acerca de las prácticas que generan sentidos de lugar y pertenencia entre distintos grupos. En línea con el acento lingüístico de la época, algunas obras de Michel de Certeau $(1975,1980)$ comienzan a lidiar con nociones quizás más abstractas de lo que significa el lugar de la historia y la creación de espacios a través de la tarea narrativa (The writing of history), para continuar con un trabajo (The Practice of Everyday Life) que decididamente aborda la construcción de espacios reales como las ciudades, aún cuando se apoya mayormente sobre el campo discursivo. En el apartado Spatial Practices (Part III), De Certeau (1980) examina la relación entre el itinerario y el mapa como prácticas discursivas que, siendo originalmente dependientes la una de la otra, se encuentran luego desconectadas. Es decir, por un lado existirían los itinerarios -el graphic trail de las prácticas espaciales- que consisten en descripciones pero también en la activación de una cierta memoria y apropiación a través de acciones como las de caminar, explorar, reconocer, o bien nombrar, escribir, actualizar, recordar y alterar historias que suceden en lugares-espacios. Por otro lado, estarían los mapas que, tratándose también de un lenguaje simbólico y antropológico para referirse al espacio, no podrían en virtud de la totalización de la imagen dar cuenta de una serie de operaciones -de borrado, transgresión, y toma de decisiones- que suceden al nivel del itinerario. El mapa resulta de estas operaciones, es un producto de ellas pero las elimina de sí o, según De Certeau, el mapa coloniza el espacio del itinerario, colapsando en el mismo plano espacios heterogéneos -distintos relatos- y tomando el centro de la escena:

The map, a totalizing stage on which elements of diverse origin are brought together to form the tableau of a "state" of geographical knowledge, pushes away into its prehistory or into its posteriority, as if into the wings, the operations of which it is the result or the necessary condition. It remains alone on the stage (De Certeau, 1980: 121).

De momento me interesa detenerme en las definiciones o categorías de lugar (place), espacio (space) y región a las que el autor arriba a partir de esta reflexión sobre los vínculos entre distintos registros de prácticas espaciales. El espacio, 
1. Aunque no sin antecedentes fundamentales anteriores, como "La producción del espacio" de Henri Lefebvre (1974). concluye De Certeau (1980: 117), es el lugar practicado. Esto se comprende al considerar el lugar como una especie de orden a partir del cual los elementos son distribuidos en una relación de coexistencia, siendo imposible su superposición. Se trata de una configuración de posiciones que trae consigo la idea de estabilidad. El espacio entonces existe cuando se toman en consideración vectores de: dirección, velocidad y variables de tiempo, o en palabras del autor,

space is composed of intersections of mobile elements. It is in a sense actuated by the ensemble of movements deployed within it. Space occurs as the effect produced by the operations that orient it, situate it, temporalize it, and make it function in a polyvalent unity of conflictual programs or contractual proximities (De Certeau, 1980: 117).

Por último, destaco la categoría de región, dado que es la que prefiero, en tanto aquel lugar donde programas y acciones interactúan (De Certeau, 1980: 126). Con una evidente influencia del pensamiento fenomenológico de MerleauPonty, las ideas de Michel de Certeau a comienzos de la década del ochenta se convierten en puntos de partida -para emplear una metáfora del itinerario- que permitirán otros desarrollos en campos variados. La discusión al respecto del significado y uso de cada una de estas categorías está lejos de cerrarse, como lo demuestran obras recientes que abogan por un entendimiento muy específico de las nociones de espacio, lugar y territorio (Duarte, 2017).

Desde la etnología, la compilación Senses of Place, editada por Steven Feld y Keith Basso (1996), es una obra pionera de lo que se llamaría en adelante la antropología del lugar y ofrece un buen resumen de varios movimientos intelectuales. Por un lado, se reconoce el surgimiento de una geografía cultural que, influenciada por las ideas filosóficas de Martin Heidegger, reflexiona sobre el concepto de morar (dwelling) en tanto habitar un espacio de sentido, con autores como Bachelard, Buttimer, J. Jackson, Cosgrove, Lowenthal, Relph, y Tuan. Seguidamente, ${ }^{1}$ una corriente de crítica neo-marxista representada por Hills, Mitchell, Turner, Harvey, entre otros, atiende desde la teoría global postmoderna a las geografías de lucha y resistencia, analizando dinámicas de género y otras diferencias políticas a partir del pensamiento de Michel Foucault (1995) sobre el panóptico y las heterotopias. La propuesta de Feld y Basso (1996) consiste en delinear una etnografía de los lugares en donde las prácticas efectivas por las cuales los grupos se vinculan con los espacios que habitan sea llevada al frente del análisis, por oposición a etnografías en donde la categoría de espacio se encontraba diseminada y sin tratamiento específico. Tal como señala Clifford Geertz en el cierre de la obra (1996: 262), la categoría de "lugar" dice poco en abstracto, y por eso resulta necesario trabajar conceptualmente la premisa de que "nadie vive en el mundo en general", sino en mundos socialmente materializados, o podríamos pensar en espacios practicados. Más allá del abordaje de este trabajo, me interesa destacar un momento en las humanidades en que la preocupación por ideas, prácticas y documentos que dieran cuenta de distintas representaciones de espacios y lugares se encontraba en una fase muy prolífera.

Como parte de este renovado punto de vista, y de manera conjunta con algunas otras corrientes de pensamiento a las que me referiré más adelante, algunos de los artefactos $u$ objetos culturales que pasan a ser re examinados son los mapas y planos, el objeto de nuestro estudio, a los que elijo llamar por el momento registros cartográficos. Estos documentos constituyen un corpus tan vasto y heterogéneo que se vuelve imposible nombrarlos sin comenzar por una serie de consideraciones. La primera es evitar la palabra mapa como categoría primaria, entendida en el sentido común -y por la Real Academia 
Española- como la representación geográfica de la Tierra o una porción de ella en una superficie plana. Esta definición no sólo deja fuera una serie de documentos que comparten convenciones cartográficas de espacios reales -como los diagramas de subte, los planos de un edificio y hasta el pronóstico del tiempo- sino que también excluye otras formas de producción de registros que no se sustentan en una superficie plana, como el ejemplo clásico de los kipus andinos, pero también las proyecciones no consumadas sobre territorios reales, narraciones orales y otras prácticas de tránsito y ocupación de espacios reales. Complementar el término mapa como referente con la idea de registro cartográfico consiste en un paso intermedio que apunta hacia lo que me gustaría pudiera convertirse en una discusión acerca de procesos cartográficos. Lo primero es reconstruir parcialmente el itinerario histórico de estos objetos culturales o al menos algunos de sus mojones principales, prestando atención ahora a la intersección entre la cartografía crítica y los estudios coloniales.

\section{Historias cartográficas, historias coloniales}

En una revisión acerca de los problemas y posibilidades de la cartografía en América Latina, la geógrafa Carla Lois (2014: 95) se refiere a la sola mención de John Brian Harley como un elemento aglutinador e incluso una "especie de contraseña que delata la pertenencia a un bando" empleada comúnmente por profesionales de diversas disciplinas que se reúnen en torno al interés por los mapas. No puedo menos que abonar a este grupo de pertenencia, ya que aún cuando las respuestas harlianas nos resultan hoy insuficientes, es innegable que la fuerza de sus preguntas alteró de manera irreversible el campo de la cartografía y generó profundos ecos en otras disciplinas. A partir de 1970, Harley comenzó a desarrollar una historia de la cartografía que descubrió las decisiones políticas constantes implicadas en la confección de un mapa, los postulados ideológicos que sustentan su producción y distribución, y los silencios que habitan estos documentos. Hasta ese momento los mapas eran empleados bien como instrumentos decorativos adornando una narrativa historiográfica, o bien como evidencias de localización geográfica precisa de lugares y personas, otorgándoles un valor de verdad científica que resistía toda crítica. Gracias a conceptos como el de ficción controlada Harley ([1988] 2005: 140) fue capaz de desarmar los valores absolutos de verdad que los mapas aparentaban en virtud de una técnica y un lenguaje específico que, consolidado alrededor del siglo XVIII, vinculó a la cartografía con las disciplinas duras, objetivas, racionales, de las ciencias naturales. La idea del mapa como una ficción revela no sólo su costado discursivo, sino lo que el autor considera su paradoja esencial; vale decir que en la medida en la que la cartografía se volvió más "objetiva" debido a las técnicas y tecnologías posibilitadas por el financiamiento de los Estados modernos, se convirtió en un instrumento de éstos para el despliegue y reproducción de la ideología dominante. Desde otra corriente intelectual, Walter Benjamin (1968: 256) sostenía que cualquier documento de la civilización es al mismo tiempo un documento de la barbarie. Aunque lo que entendamos por cada uno de esos colectivos pueda variar, lo cierto es que aún mientras estos documentos fueron utilizados para reproducir la ideología dominante, albergan dentro de sí potencias opuestas que pueden ser puestas al servicio de otras causas. De esta manera, la inquietud no reside ya en lo cierto o falso de un mapa, sino en aceptar su carácter ficcional en tanto perspectiva del mundo en el momento en el que fue realizado, y en adelante interrogar al mapa como acción más que como una descripción impasible de un espacio real. La reinserción de los mapas en una red de textualidades fue realizada a partir 
2. Me gustaría pensar que Harley se vio interpelado por la "lectura a contrapelo" propuesta por Guha (2009) en la década del ochenta, pero no encuentro evidencia en sus artículos que apoye una relación explícita con el Grupo de Estudios Subalternos. del rechazo de la cualidad mimética -es decir, la suposición de que los mapas son capaces de representar en menor escala una superficie de la Tierra- y a través de la incorporación de ideas que en esa década circulaban ampliamente por el ámbito académico, principalmente las de Roland Barthes ([1980] 2010) y Michel Foucault (1995). Entenderlos como un texto abre el juego a conceptos instrumentales como el de silencios cartográficos, con especial atención a los silencios estratégicos. Es aquí, quizás, donde se encuentre mejor resumido el germen de su propuesta; quiero decir, un análisis que sospeche de la textualidad e intente leer a contrapelo ${ }^{2}$, o entre líneas, los mensajes que el documento vehiculiza por un lado y al mismo tiempo oculta, por el otro. Para hablar de los silencios, el autor se apoya tanto en una percepción filosófico-lingüística (Barthes) como en la sociología del poder (Foucault). De la primera vertiente concluye que el silencio es tan expresivo como cualquier otro fragmento del discurso y debe ser esperado en cualquier acto de comunicación. De esta manera sabemos que aquello que no está en los mapas constituye un objeto de estudio tan meritorio como aquello que efectivamente está. El silencio se considera una declaración positiva y no sólo brechas en el flujo del lenguaje: se trata en todo caso de una actuación humana activa, por oposición a la concepción de silencio como espacio en blanco, término utilizado por la cartografía clásica para dar cuenta de este tipo de manifestaciones de manera acrítica. De la sociología del poder, particularmente del pensamiento de Michel Foucault, Harley entiende al mapa como un dispositivo de poder-conocimiento. No es azaroso que la cartografía de finales del siglo XVI haya sido considerada una ciencia de príncipes, dado que los mapas eran ante todo un instrumento de poder. Las monarquías empleaban sus usos y ocultamientos de manera tal que fuera funcional a sus intereses comerciales y militares. Al mismo tiempo controlaban, seleccionaban, organizaban y redistribuían estos fragmentos de discurso según un número de procedimientos. El conjunto de procedimientos, reglas no escritas y a prioris históricos constituye la episteme que funciona por detrás de la imagen del mapa (Foucault, en Harley [1988] 2005: 117).

La influencia del pensamiento derridiano en esta voluntad de deconstrucción es evidente, y aún más si consideramos que uno de los primeros y más influyentes artículos de Harley fue precisamente "Deconstructing the map" ([1989] 1992), donde el objetivo de romper con el vínculo realidad/ representación que se daba por sentado en la utilización de estos documentos es primordial. Esta tarea es compartida por algunos de sus contemporáneos, entre ellos Denis Wood (1992), cuyo libro The Power of Maps se posiciona como un verdadero manual de construcción -y deconstrucción- cartográfica. Del todo ligado al vocabulario y técnicas geográficas, Wood realiza un estudio extensivo de distintos tipos de documentos cartográficos, atendiendo a su composición en términos de técnica, eficacia y significado dentro de la imagen; pero también de sus ámbitos de producción y circulación, donde la imagen es consumida. Esto resulta en, por ejemplo, un análisis ejemplar acerca de cómo cada signo que se emplea en la confección de un mapa posee una historia propia, y de qué manera opera ese signo en relación a otros para servir un interés que moviliza el mapa. Al comienzo de la obra el autor lo deja bastante claro, "power is the ability to do work. Which is what maps do: they work" (Wood, 1992: 1). Sostiene que funcionan o trabajan en al menos dos sentidos: por un lado, operan efectivamente, no fallan, y generan efectos. Por el otro, según el autor, los mapas sudan, se emplean, se aplican para un fin que no es otro sino mantener la incesable reproducción de la cultura que les da origen.

Algunas de estas ideas pueden resultar obvias para lectores familiarizados con la influencia del giro lingüístico en el estudio de distintos objetos culturales, 
pero es pertinente recordar que la aparente naturaleza de los mapas -esto es, su marcación como productos técnicos especializados y neutrales- los mantuvo tradicionalmente al margen de análisis políticos e ideológicos e implicó una resistencia mayor que Harley (2005) y otros se dedicaron a desmontar sistemáticamente. Gracias a la influencia del legado harliano, quedan asentadas algunas premisas acerca de las cuales hoy existe un consenso, al menos entre aquellos interesados en la historia de la cartografía, a saber: a) el mapa es inexacto por naturaleza, b) el mapa es un instrumento de poder y c) el mapa es una operación teórica (Lois, 2014: 27). Como es evidente, tanto Harley ([1988] 2005) como Wood (1992) trabajan a partir de la idea de mapa como categoría primaria, aunque complejizan el entendimiento de este documento a partir de una serie de metáforas y conceptos sumamente críticos con respecto a la definición enciclopédica. Considero que, además de enunciar el santo y seña, posicionar a J. B. Harley (2005) como puntapié inicial es una forma de valorizar un movimiento que lo trascendió ampliamente en la historia de las ideas acerca del espacio y su representación. Regresaré más adelante a otras críticas que incluso los sucesores de Harley postularon y el camino hacia lo que algunos consideran un nuevo paradigma -ciertamente una nueva perspectiva- en la historia de la cartografía. Por ahora continuaré con algunos vínculos entre el pensamiento harliano y una serie de movimientos que sucedían de manera simultánea en el campo de los estudios culturales y coloniales.

En el caso de los mapas, planos y otros registros coloniales, existen razones históricas que confieren a estos documentos un lugar específico dentro de la narrativa de despojo, conquista y colonización, e incluso en la formación de estados nacionales. Me refiero a que es posible poner un pie en el territorio sólo porque es posible poner un dedo en el mapa o, en palabras de Barbara Mundy (1996: 87), es preciso imaginar una región para mapearla y viceversa. Cuestionar la manera en la que estas imágenes representan los espacios y a las personas; es decir, lo que deliberadamente muestran y ocultan, es una tarea a la que nos damos aún no sin contar con sólidos antecedentes en el campo. Mundy (1996) es uno de ellos, a partir de una obra que revisa exhaustivamente los registros visuales y documentales producidos a partir de los cuestionarios de las Relaciones Geográficas de Indias enviados a los oficiales coloniales de Nueva España. La autora analiza la participación indígena en la autoría de los mapas $y$, antes que eso, lo que mapear significaba para un linaje de reyes españoles, cuáles eran sus expectativas al enviar estos cuestionarios y de qué manera los proyectos fueron intervenidos por una participación indígena inesperada. Sin anticiparse a la autoría nativa, los cosmógrafos españoles recibieron documentos que no sólo mostraban una parte del mundo que desconocían, sino un punto de vista para la representación espacial que tenía algunas marcas de la tradición europea pero era decididamente otra manera de pensar y hacer visible el espacio. Walter Mignolo (1999) fue otro de los primeros críticos de la cartografía colonial y de su utilización como herramienta de dominación colonial. ${ }^{3}$ El núcleo de su planteo reside en la coexistencia inicial de formas diversas de conceptualizar el espacio -de hecho, el espacio, el tiempo y el mundo, pero para el caso de los mapas, digamos el espacio-, que son negociadas en el campo de la representación y cuya puja podemos evidenciar en el producto cartográfico. Su corpus en este caso lo constituyen exclusivamente mapas, y gracias a ello contamos con algunas diferenciaciones útiles para seguir trabajando con estos documentos; a saber, que aún cuando el mapa no es el territorio, se convierte en él cuando los miembros de una comunidad lo aceptan e instrumentan como herramienta para controlar territorios, colonizar mentes e imponerlo a los demás miembros; o dicho de otro modo, que las construcciones imaginarias toman dimensiones ontológicas con el
3. La influencia de J. B. Harley y Denis Wood en su trabajo es explícita. 
tiempo y de esta manera las descripciones de un objeto se convierten en el objeto mismo (Mignolo, 1999: 227, 237). Es interesante que De Certeau (1975), Mundy (1996) y Mignolo (1999) también se detengan en la diferencia entre la confección de mapas y otros registros escritos, y del mismo modo concluyan que en el mapa la distribución de poder es al menos distinta. Mignolo (1999) sugiere que en situaciones coloniales, mapear y nombrar son a la territorialidad lo que las gramáticas son a la lengua amerindia y la narrativa histórica a la memoria indígena; es decir, el mismo tipo de movimiento de apropiación y dominación. No obstante,

while writing the grammars of Amerindian languages and the histories of their memories challenged both the grammarian and the historian, verbal geographical descriptions and maps overpowered, so to speak, Amerindian pinturas and territoriality (Mignolo, 1999: 296).

Mignolo (1999) considera, al igual que De Certeau (1975), que el mapa es de alguna manera más efectivo a la hora de imponerse sobre las distintas concepciones del mundo que se negocian en el escenario colonial. Este planteo desestima el mito de conquistadores que simplemente desconocían la territorialidad indígena y en tanto eso impusieron su propia visión sobre una especie de vacío. Mundy (1996) explícitamente sugiere que los indígenas fueron convocados para realizar los mapas de los cuestionarios, y Mignolo se encarga de dejar en claro que fueron acciones conscientes -tales como la omisión o el borrado- las que produjeron los mapas coloniales, y en este sentido se reconoce el diálogo con J. B. Harley y su teoría acerca del silencio como una manifestación del poder dentro del mapa. En última instancia, De Certeau (1975), Harley ([1988] 2005), Mundy (1996) y Mignolo (1999) acuerdan en algo fundamental: las representaciones se convierten en performances de la colonización, y por eso es importante regresar a los mapas -y extendernos a otras formas, si fuera posible. A riesgo de sonar reiterativa, insisto en estas coincidencias porque conducen hacia el problema que guía parte de mi investigación, ${ }^{4}$ y es cómo desarticular las redes que convierten a estos y otros elementos de la semiosis colonial en objetos culturales poderosos y efectivos quizás por sobre otro tipo de discursos de los que en las ciencias sociales ya estamos acostumbramos a sospechar desde hace algunas décadas.

Continuando esta línea desde los estudios coloniales, Gustavo Verdesio (1997) plantea una interesante revisión de la propuesta de Mignolo (1999) y nos propone pensar la territorialidad como práctica en un sentido más amplio que el que refiere a su representación en mapas y planos. En un artículo temprano que analiza específicamente representaciones territoriales del Uruguay colonial, plantea la síntesis de los problemas y propuestas que se encontrarán desplegadas en trabajos posteriores, al menos acerca de la concepción del espacio amerindio. Es decir, a partir de una serie de representaciones visuales y escritas, analiza los mapas producidos por los conquistadores siguiendo la propuesta de Mignolo (1999), pero en un momento dado -cuando toca estudiar la concepción nativa del espacio- realiza un quiebre en la narrativa: no alcanza con comparar objetos culturales durables -como mapas y planos- planteados en una relación natural de equivalencia, dado que este ejercicio excluye las concepciones territoriales de aquellos grupos sociales que, por distintos motivos, no tuvieron interés o necesidad de transmitir su conocimiento acerca del espacio en superficies durables. En este trabajo esboza una propuesta que involucra el reconocimiento de prácticas territoriales planteado por De Certeau (1975), y apunta hacia la identificación de distintas concepciones espaciales, intuyendo que el texto no es el final del camino en nuestra tarea de interpretar 
pero sin plantear aún una agenda específica. En otro trabajo, Verdesio (2001a: 145) retoma este problema, aunque se refiere sólo al final a la cartografía como una herramienta privilegiada para representar y controlar las tierras que los conquistadores poseían. El tratamiento es breve pero contundente, yendo directo a la facultad de los mapas para homogeneizar el paisaje amerindio sobre la idea de un espacio en blanco que es inscripto por los conquistadores, dejando fuera toda agencia o incluso presencia de los grupos nativos. Se detiene en esto para contraponer la mirada geográfica (geographic gaze) que organiza las tierras para demarcar y poseerlas, para dotarlas de sentido ante el sujeto europeo, con otra imagen del territorio que nos es dada a través de las ocupaciones, concepciones y prácticas que los grupos nativos elaboraron en y de los espacios. En un mismo movimiento, el autor plantea el problema de la cartografía sólo para proponer de inmediato una alternativa, el acceso a estos saberes a partir de la arqueología y las crónicas, continuando de alguna manera esa agenda comenzada antes. Especialmente en lo que refiere a la arqueología como vía de acceso a la materialidad de grupos cazadores recolectores prehispánicos, la propuesta es innovadora y significa un paso adelante en la discusión acerca de la territorialidad nativa. En otro trabajo que complementa al anterior, Verdesio (2001b: 92) se encarga de clarificar sus críticas a Mignolo, aun considerando el valor de comparar distintos objetos culturales o semióticos nativos con representaciones planas producidas por una episteme occidental, pero entendiendo este ejercicio como una agenda limitada. Quiere decir que comparar objetos o representaciones en superficies durables aún conlleva una limitación impuesta por el pensamiento occidental: la necesidad de producir un objeto-mapa -producto de un mapmaking- que se plantea como condición excluyente. El autor diferencia esta producción de la actividad de mapeo (mapping) que efectivamente es inherente a todos los grupos sociales y tiene que ver con pensar el propio espacio, resulte eso o no en la producción de un objeto durable. Esta distinción entre mapping y mapmaking establece que poseer conocimiento de un territorio es muy distinto que transmitirlo, y la vía cartográfica está lejos de ser la única forma de transmisión, pero sí se trata de una mirada colonial que condiciona nuestro conocimiento del espacio. Los espacios cuentan una historia a través de prácticas de ocupación en clave histórica, como lo son la producción y uso de cerritos (mounds) por grupos nativos pero también por otros grupos que hoy habitan el territorio uruguayo. En todo caso, y considerando la necesidad efectiva de un plan de trabajo, el autor propone una cartografía que esté al servicio de la corografía nativa, un conocimiento local y específico acerca del paisaje que contemple las prácticas territoriales a lo largo de la historia y se sirva de otras fuentes para trazar su propia genealogía. Destaco aquí la obra de Jeff Erbig (2020), quien aceptando el desafío condujo una investigación que realmente pone la cartografía reglada por una episteme occidental al servicio de la reconstrucción cuidadosa de formas de ocupación, circulación y movimientos de grupos nativos en el espacio amerindio. También, los trabajos de autoras como Perla Zusman $(2001,2013)$ y Maria de Fatima Costa (2007) que reflexionan desde distintas perspectivas sobre la relación entre eventos geográficos y su incorporación en los imaginarios cartográficos y espaciales.

El repaso realizado presenta sólo una porción de un campo de debates más amplio, ya que ninguno de los autores que intervienen han investigado en soledad, y las influencias y conexiones probablemente sean más de las que puedo dar cuenta aquí. Sin embargo, explicitar una breve genealogía colabora con elicitar un punto de inserción personal. Si es que, como parecerían acordar estos autores, existe una especie de plusvalía en el mapa como representación orientada a la dominación de un referente -sea un espacio, grupo, lengua, etc.-, 
entiendo que este valor diferencial se alberga en su naturaleza visual, allí donde encontramos el límite de la metáfora textual o, mejor dicho, un poco más allá del límite. Sigue entonces una discusión que podrá acercarnos a ese otro lado de las imágenes que nos interesan.

\section{Un enfoque visual}

El encantamiento que produce el primer contacto con la cartografía crítica de la mano de J. B. Harley ([1989] 1992) es innegable, siendo éste quizás uno de los campos que más se benefició del giro lingüístico. No obstante, este tipo de lectura centrada en la textualidad condujo a una subestimación del carácter visual de los mapas. Cuando el mapa se convierte en texto -o en ficción controlada-, se desestima en el mismo gesto el hecho de que, además de estar teñidos de una cierta ideología dominante que los produce y los necesita, además de servir intereses específicos, además de estar sesgados por los valores de sus autores; es decir, además de compartir un número de características con cualquier documento escrito, los mapas son también otra cosa. Antes que nada, un mapa es una imagen. Ya no imágenes decorativas que ilustran silenciosos los manuales de historia, sino objetos completos que forman parte, y son susceptibles, de ser entendidos desde la cultura visual. Con la llegada del llamado giro pictórico, los mapas y otros documentos cartográficos son sujetos de una relectura que, en virtud de lo que considero una naturaleza híbrida, reúne a profesionales de distintas disciplinas.

En Argentina, Carla Lois se encargó de plantear una discusión que sucede en gran medida en el circuito académico anglosajón, participando de ella al mismo tiempo que la hizo más accesible para otros. En su trabajo como historiadora de la cartografía argentina señaló las limitaciones del giro lingüístico, al mismo tiempo que valoró sus aciertos y los puso en diálogo con una producción más reciente que orienta su investigación (Lois, 2014). La autora comparte con la tradición harliana el deseo de sacar la cuestión cartográfica del plano de las representaciones técnicas del territorio, pero su acento en la dimensión pictórica la lleva a proponer relaciones de tensión y diálogo entre los mapas y otras imágenes que tejen imaginarios sobre la Argentina moderna. Su propuesta de revisitar estas imágenes desde los estudios visuales se funda en la necesidad de "hacer hablar a los mapas", algo que el tipo de análisis lingüístico habría sido incapaz de hacer en virtud de su incapacidad para dar cuenta de los pliegues de la cuestión visual que atraviesan todas las disciplinas (Lois, 2014: 27). La tarea de reconectar al mapa con otros objetos culturales; es decir, hacerlo sujeto de estudios visuales, se enmarca en lo que llama la "reactivación de un movimiento pictorial" ${ }^{5}$ (Lois, 2014: 28) en una época oculocéntrica, signada por el permanente estímulo y alta circulación de imágenes. Por su parte, Matthew Edney (1997) compara la cartografía con la pornografía, sugiriendo que como tal no hay nada estrictamente pornográfico -Roland Barthes ([1980] 2010) diría ni siquiera erótico- en una imagen, tampoco hay una mapidad intrínseca, sino que son modos de mirar en los que existe una relación de poder entre el sujeto y lo mirado. Edney empuja el argumento planteando que en esa mirada pornográfica y cartográfica operan mecanismos similares, como la sujeción a una mirada asimétrica y dominante, la objetivación de partes que definen el todo, y la imposición del deseo de quien mira (Edney, en Lois 2014: 29). Más allá de la provocativa comparación está la idea de la mapidad, o lo que es un mapa, como una cualidad que no define quien produce la imagen sino el uso que un lector le da, y los contextos en los que interviene. Decir que esta idea dialoga con aquellas de Mignolo (1999) y Verdesio (2001a) quizás parezca

5. Esta línea de pensamiento tam pensamiento derridiano, tal como Harley ([1989] 1992) ubicaba las suyas en la idea de deconstrucción. $O$ bien esto habla de la amplitud y exibilidad del pensamiento quizás tambien noda despreciab go acerca de la continuidad de ideas que contradice la noción de cambio de paradigma. 
forzado, pero ciertamente las hago dialogar porque existe una atención que se desplaza desde la imagen cartográfica en una superficie plana hacia el sujeto que la mira, la produce, la interpreta, e incluso al sujeto que no la necesita, que produce otras formas de mapmaking o ninguna, al que no encuentra mapidad mirando un mapa pero sí puede hallarla en otro lugar.

En el campo de los estudios visuales contamos con ya clásicos autores a partir de los cuales podemos intentar articular la naturaleza de las relaciones entre la imagen y quien la ve o interpreta, si es que ver no es creer sino interpretar (Mirzoeff, 2011: 34). Me refiero a Georges Didi Huberman (2008), Jacques Rancière (2008) y Roland Barthes ([1980] 2010), quienes a partir del trabajo con objetos materiales distintos reconocen sin embargo que una característica inherente de la imagen es su falta de compleción. Estos autores depositan en el espectador o consumidor de la imagen la responsabilidad de completar el sentido o de permitir que la imagen funcione. Al respecto, Rancière (2008: 107) retoma un término presente en Barthes ([1980] 2010: 38): el de imagen pensiva. Barthes decía que una fotografía no es subversiva cuando asusta, repele o estigmatiza, sino cuando piensa. La manera en que una imagen piensa es a través de su indeterminación, existe algo que nos perturba en ella, algo que va más allá de lo que podemos saber y nombrar (studium), algo que nos molesta (punctum), que nos habla personalmente y que completamos, dice el autor, cuando finalmente retiramos la vista de la imagen, cuando cerramos los ojos para verla. Rancière (2008) continúa con esta línea e insiste con que la responsabilidad de una imagen no corresponde sólo al autor, no obstante altera la idea de imagen pensiva, o la desarrolla, al decir que no es la imagen la que piensa, sino que es la que contiene un pensamiento no pensado (unthought thought) destinado a encontrarse con la mirada de un espectador emancipado. En sus palabras:

Emancipation begins when we understand that viewing is also an action that confirms and transforms this distribution of positions. The spectator also acts, like the pupil or scholar. She observes, selects, compares, interprets. She links what she sees to host other things that she has seen on other stages, in other kinds of place (Rancière, 2008: 13).

Por su parte, Didi-Huberman (2008) dialoga permanentemente con la idea de imagen dialéctica de Benjamin (1968) al hablar de una imagen ardiente. Lo que arde en la imagen es lo real, es aquello que todavía no es ceniza, aquellas imágenes que aún no se han perdido para siempre porque las hemos recuperado, que con su sola existencia nos hablan de las otras, las que han ardido a lo largo de la historia. "La imagen es algo muy distinto de un simple recorte realizado sobre los aspectos visibles del mundo [...] Es ceniza mezclada, hasta cierto punto caliente, que proviene de múltiples hogueras" (Didi-Huberman, 2012: 42). Mirar, para este autor, no equivale tampoco a ver sino que supone el reconocimiento de una implicación y una afectación por parte del sujeto. Saber mirar una imagen sería, en cierto modo, ser capaz de distinguir ahí donde la imagen arde, ahí donde su eventual belleza reserva un lugar a un signo secreto, a una crisis no apaciguada, a un síntoma. Entonces, para pensar estas imágenes, conviene tener en cuenta nuestra acción de verlas, seleccionarlas, hablar de ellas. Edney (1997) sugiere que la noción de mapidad se desarrolla también en este sentido, dado que no sería una cualidad que resida en la imagen sino en la actividad de interpretarla como mapa. Se trata de algo que completamos al ver la imagen, no algo que en ella exista.

Revisitar los registros cartográficos a partir de los estudios visuales nos permitiría abrir la definición clásica y sumamente restringida de mapa para en 
cambio, pensar problemas transversales como la lógica de representación entre la imagen y el referente que evoca. El objetivo es expandir el universo de objetos pasibles de ser pensados y examinados en clave cartográfica, una meta que no es ajena a aquellos que buscaron revisitar el corpus en estudios coloniales. Como estos, es preciso actualizar la importancia de las prácticas materiales en la producción de estas imágenes. Las ideas de Kitchin y Dodge (2007) que postulan al mapa como un permanente ejercicio de reterritorialización que nunca alcanza estabilidad, que siempre está siendo cuestionado en su uso, me recuerdan al menos a la relación entre el mapa y el itinerario que De Certeau (1975) dejó planteada hace bastante tiempo. En esta definición, el mapa se vuelve

Un conjunto de puntos, líneas y colores que toma forma como -y que es entendido como- un mapa a través de prácticas de mapeo (una inscripción en constante estado de reinscripción). Sin estas técnicas, una representación espacial es simplemente tinta coloreada sobre papel. Esas prácticas basadas en conocimiento y habilidades aprendidos hacen de la tinta un mapa, y esto ocurre, una vez que tal contrato se asume: un conjunto de puntos, líneas y áreas es reconocido como un mapa, es interpretado, traducido, y hecho para trabajar en el mundo. Como tales, los mapas están permanentemente en estado de transformación, son permanentemente re hechos y reformulados"6 (Kitchin y Dodge, 2007: 335, en Lois, 2014).

Partiendo de este acuerdo, me pregunto qué nos aporta entonces el giro pictórico, qué nos permite ver que antes no veíamos. Lois (2014) realiza deliberadamente una lista de préstamos, tres para empezar, que los estudios cartográficos podrían realizar para interrogar de otro modo a su objeto. Estos son la noción de mímesis, la metáfora del espejo y la ilusión de realidad. Destaco estos préstamos como una manera de arrojar al mapa a otra serie de imágenes, y a la vez permitir la entrada de éstas a cierto agrupamiento cartográfico. Ya no se trata de decir si el mapa es una imagen técnica o política, neutra o ideológica. Se trata de comprender qué nos permite ver y cómo lo hace, cómo podemos actuar a través de lo que vemos en los mapas. El funcionamiento cultural del mapa es lo que precisa ser desmontado, y los análisis de otros objetos visuales pueden ofrecernos modelos para este ejercicio. Para esto, Lois (2014) trae a la discusión las notas de Giorgio Agamben (2011) sobre el concepto de dispositivo de Michel Foucault, en tanto estrategias de relaciones de fuerza que soportan y son soportadas por diversos tipos de saberes. Estos dispositivos alteran las formas del mundo en que vivimos y son puestos en práctica con fines útiles -como diría Wood (1992), trabajan. En esta línea puede posicionarse el trabajo del teórico de la cultura visual Nicholas Mirzoeff (2011), quien continuando la tradición de algunos investigadores aquí mencionados, principalmente W. J. T. Mitchell, se preocupa por destacar la complejidad de las imágenes al punto de plantear que constituyen un archivo en sí mismo (Mirzoeff, 2011: xv) y, lo que es más, un archivo a través del cual podemos acceder a historias subalternas que se encuentran silenciadas en los documentos escritos. El autor toma el caso de las plantaciones de esclavos en la América colonial como locus primario del despliegue de lo que llamará la producción de visualidad (visuality). Esto es, la visualización de procesos históricos de manera tal que la autoridad se muestre como evidente o naturalizada mientras crea visual y discursivamente sus otros internos -y subalternos. Siguiendo también una perspectiva foucaultiana, propone que los complejos de visualidad (visual complexes) están histórica, local y socialmente determinados, pero en todos los casos funcionan a partir de tres procesos principales: primero la clasificación de un grupo de personas -a través de los actos de nombrar, clasificar y definir-; luego la separación de 
este grupo como forma de organización social, con la intención de crear una segregación que evite la organización política de estos sujetos; y finalmente hace que esta clasificación y separación sean tomadas como el orden natural de las cosas, una estetización del statu quo (Mirzoeff, 2001: 3). Este tipo de análisis puede enriquecer el entendimiento de los registros cartográficos, en tanto "the authority of coloniality has consistently required visuality to supplement its deployment of force. Visuality sutures authority to power and renders this association "natural'" (Mirzoeff, 2001: 4). La atención hacia las imágenes como engranajes de un dispositivo que las pone en funcionamiento en compañía de otros objetos culturales es uno de los aportes fundamentales de esta renovada mirada crítica desde los estudios visuales.

\section{Conclusiones}

En este artículo intenté realizar un acercamiento hacia una discusión que tiene como centro al mapa y otros registros cartográficos. Comenzando por un recorrido acerca de algunas ideas fundamentales en el pensamiento de los espacios y su representación, continuando con el tratamiento específico de los registros coloniales y concluyendo en un campo de los estudios visuales y cartográficos. Entiendo que no existe una disrupción entre estas corrientes, sino una conversación que en ocasiones resulta demasiado espaciada. Al articular estos aportes en un argumento, podemos evidenciar que los puntos de contacto acerca del valor de estas imágenes y la complejidad que conllevan son numerosos. No obstante, el mismo ejercicio de agrupar ciertas ideas conduce a pensar que podrían tener un mejor diálogo interdisciplinar.

Entiendo que los estudios coloniales, culturales y cartográficos necesitan incorporar las prácticas territoriales o itinerarios que han sido discutidos al principio, para de esta manera ampliar el entendimiento hacia otros objetos culturales que no responden a la definición estricta de mapa. Aún, las representaciones visuales en superficies planas no dejan de ser un componente central del corpus de nuestras investigaciones y, en muchos casos, orientan la lectura de otras fuentes de primera mano y bibliografía específica. Por esto existe un valor en interpretar su carácter textual a partir de los aportes de la cartografía crítica que es innegable. Sin embargo, la discusión que se viene dando hacia el interior de los estudios coloniales podría beneficiarse del enfoque renovado que propone una corriente de la cartografía con una fuerte influencia de los estudios visuales, que nos permite dilucidar nuevas capas de significado y formas de agrupación en estos documentos a partir de su composición en tanto imágenes.

En resumen, la discusión intenta proveer un terreno para reflexionar no sólo acerca de la producción de objetos durables que guían relaciones espaciales en una geografía dada, sino también de la posibilidad metodológica de conjurar una comunidad de imágenes como un corpus válido para la investigación etnohistórica. Estas imágenes producen sentidos propios -aisladamente y en conjunto- y colaboran de manera visual con la empresa conquistadora. Los registros son cartográficos porque forman parte de un contrato dentro del cual su papel es ordenar relaciones espaciales. La mapidad en ellos está otorgada por el grupo que la produce y consume, pero no es su única cualidad. Un ejercicio posible dentro de nuestra agenda pendiente sería tomarse en serio la tarea de comparar y utilizar estos registros como fuentes de información acerca de la imaginación geográfica y cartográfica a lo largo del tiempo para una región dada. Una primera aproximación a este intento para la región chaqueña comienza a revelar la complejidad de estos documentos, en tanto nunca 
dos registros representan el mismo territorio, no importa que tan próximos espacial y temporalmente se encuentren. La imagen funciona en distintos niveles, y las relaciones que ordena no son sólo espaciales o miméticas en relación a una porción de la Tierra, sino que dispone y moviliza imágenes que avalan el empleo de acciones efectivas sobre los territorios y las personas. Por último, estas imágenes construyen una capa de visualidad sobre la cual se construyen otras, una especie de consenso en torno a una forma de imaginar una región y sus habitantes, una imagen que dialoga con otras a través del espacio y el tiempo. 


\section{Bibliografía}

Agamben, G. (2011). ¿Qué es un dispositivo? Sociológica 26 (73): 249-264. Disponible en Internet: http://www.scielo.org.mx/pdf/soc/v26n73/v26n73a1o.pdf. Consultada el: 15 de mayo de 2020.

» Barthes, R. ([1980] 2010). Camera Lucida: Reflections on Photography. New York, Pbk. ed. Hill and Wang.

» Benjamin, W. (1968). Illuminations. New York, Harcourt, Brace \& World, New York. (1St ed.).

»Certeau, M. de (1975). The Writing of History. New York, Columbia University Press.

»Certeau, M. de (1980). The Practice of Everyday Life. Berkeley, University of California Press.

» Costa, M. (2007). De Xarayes ao Pantanal: a cartografia de um mito geográfico. Revista do Instituto de Estudos Brasileiros (45): 21-36. Disponible en Internet: https://doi. org/10.11606/issn.2316-901X.voi45p21-36. Consultada el: 15 septiembre de 2020.

»Didi-Huberman, G. (2008). Images in spite of all: four photographs from Auschwitz. Chicago, The University of Chicago Press.

»Duarte, F. (2017). Space, Place, and Territory: a Critical Review on Spatialities. London, Routledge.

» Edney, M. (1997). Mapping the Empire. The geographical construction of British India, 17651843. Chicago-Londres, The University of Chicago Press.

» Erbig, J. (2020). Where Caciques and Mapmakers Met Border Making in Eighteenth-Century South America. Santa Cruz, University of California.

» Feld, S. \& K. Basso (eds.) (1996). Senses of Place. Santa Fe, N. M., School of American Research Press.

» Foucault, M. (1995). Discipline and punish: the birth of the prison. New York, Vintage Books.

" Geertz, C. (1996). “Afterword” en Feld, S. \& K. Basso (eds.); Senses of Place: 259-262. Santa Fe, N. M., School of American Research Press.

» Gordillo, G. (2004). Landscapes of Devils. Durham, Duke University Press.

» Guha, R. (2009). The Small Voice of History. Collected Essays. Bangalore, Ranikhet/ Permanent Black. (Introduction by Partha Chatterjee).

» Harley, J. B. ([1989] 1992). Deconstructing the map. Passages. A Chronicle of the African Humanities 3: 10-13. (Reprinted from Cartographica 26 (2): 1-20.

» Harley, J. B. ([1988] 2005). "Silencios y secretos. La agenda oculta de la cartografía en los albores de la Europa moderna” en Laxton, P. (comp.); La Nueva Naturaleza de los Mapas. Ensayos sobre la historia de la cartografía: 113-140. México DF, Fondo de Cultura Económica.

" Harley, J. B. (2005). La Nueva Naturaleza de los Mapas. Ensayos sobre la historia de la cartografía. México DF, Fondo de Cultura Económica. (Compilación de P. Laxton, Introducción de J. H. Andrews).

» Kitchin, R. \& M. Dodge (2007). Rethinking Maps. Progress in Human Geography 31 (3): 331-44. Disponible en Internet: https://journals.sagepub.com/doi/ pdf/10.1177/0309132507077082. Consultada el: 1 de mayo de 2020. 
»Lefebvre, H. (1974). The production of space. Oxford, OX, UK, Blackwell.

» Lois, C. (2014). Mapas para la nación: episodios en la historia de la cartografía argentina. Buenos Aires, Biblos.

" Mignolo, W. (1999). The darker side of the Renaissance: literacy, territoriality, and colonization. Ann Arbor, University of Michigan Press. (2nd ed.).

» Mirzoeff, N. (2011). The Right to Look: a Counterhistory of Visuality. Durham, Duke University Press. Disponible en Internet: http://dx.doi.org/10.1215/9780822393726. Consultada el: 1 de mayo de 2020.

" Mundy, B. (1996). The Mapping of New Spain: Indigenous cartography and the maps of the relaciones geográficas. Chicago, The University of Chicago Press.

"Nemser, D. (2017). Infrastructures of race: concentration and biopolitics in colonial Mexico. Austin, University of Texas Press. (First edition).

» O'Gorman, E. (1958). La Invención De América: El Universalismo De La Cultura De Occidente. México DF, Fondo de Cultura Económica. (1a ed.).

" Rancière, J. (2008). The Emancipated Spectator. London, Verso.

"Seed, P. (2001). American Pentimento: The Invention of Indians and the Pursuit of Riches. Minneapolis, University of Minnesota Press.

"Verdesio, G. (1997). Las representaciones territoriales del Uruguay colonial: hacia una hermenéutica pluritópica. Revista de crítica literaria latinoamericana: 46: 135-162.

»Verdesio, G. (2001 a). Forgotten Conquests. Rereading New World History from the margins. Philadelphia, Temple University Press.

"Verdesio, G. (2001 b). Todo lo que es sólido se disuelve en la academia: sobre los estudios coloniales, la teoría poscolonial, los estudios subalternos y la cultura material. Revista de estudios hispánicos 35: 633-660.

"Wood, D. (1992). The Power of Maps. New York, Guilford Press. (With J. Fels).

"Zusman, P. (2001). Entre el lugar y la línea: la constitución de las fronteras coloniales patagónicas 1780-1792. Fronteras de la historia 6. Disponible en Internet: https://revistas. icanh.gov.co/index.php/fh/article/view/697/555 Consultada el: 15 septiembre de 2020.

»Zusman, P. (2013). La geografía histórica, la imaginación y los imaginarios geográficos. Revista geográfica Norte Grande 54: 51-66. Disponible en Internet: http://dx.doi. org/10.4067/So718-34022013000100004. Consultada el: 15 septiembre de 2020. 